"On the Physical Conditions under which the Cambrian and Lower Silurian Rocks were probably deposited over the European Area," in the Q.J.G.S. for 1875 , which has been reproduced by Mr. Walcott, along with the map and sections for other European areas, in his monograph. The main lines of division and zones remain as given in that section, but it has since been possible to make several important sub-divisions and to add new zones. ${ }^{1}$

The information obtained since the Map was published has confirmed the view I expressed in the paper that wherever the base line of the Cambrian is seen throughout the European area, it is almost invariably found to "rest unconformably upon an earlier series of rocks," and that the beds varied in thickness and character in accordance with the unevenness of the old pre-Cambrian floor and along fairly well-marked lines of depression. It is not, of course, to be expected that there should be an unconformable break between the Cambrian and Pre-Cambrian in all parts over a very large area, and $M r$. Walcott shows that there is conformity at that horizon in several districts in America. In future the faunas must determine the position where there is any doubt as to the presence of a physical break. In Britain fortunately there is evidence of a very marked break at the base of the Cambrian in all the areas examined.

\title{
IV.-Reade's Theory of Mountain-Bullding.
}

BY A. J. JUkes-Browne, B.A., F.G.S.

$\mathrm{M}^{\mathrm{B}}$

R. MELLARD READE'S book on the "Origin of Mountain Ranges" has now been before the geological public for five years; it has been reviewed in this Magazine and elsewhere, and several more or less weighty objections to the theory have been put forward; but no very complete examination of it has been attempted. This may be partly due to the manner in which Mr. Reade has presented his theory, for he has certainly been too diffuse over points which require very slight illustration and not nearly explanatory enongh on other points of great physical difficulty.

Having had occasion to pay some attention to the subject, it has seemed to me that $\operatorname{som} \theta$ of the difficulties raised by some of his critics are not so great as they imagine, while there are other difficulties which neither Mr. Reade nor his critics have sufficiently considered. It may seem rather presumptuous on my part to enter a field of controversy where such men as O. Fisher, C. Davison, and M. Reade, are the debaters, and where the chief weapons used - physics and mechanics-are such as I have small acquaintance with. But some of the questions dealt with can be handled without more than an elementary knowledge of these subjects, and I fancy there are many geologists who wish to know exactly how far $\mathrm{Mr}$. Reade's theory can be accepted as a vera causa. In what follows, therefore, I am only endeavouring to assist in forming a conclusion on this point.

1 See "The Classification of the Eozoic and Lower Palæozoic Rocks," Popular Sci. Rev. 1881, and "Recent Researches among Lower Palæozoic Rocks," Proceed. Geol. Assoc. vol. vii. 
In the first place I will deal with three objections which seem to me to be capable of being partially answered:

1. Mr. Fisher, reviewing the book in this $\mathrm{M}_{\triangle \mathrm{Gazine}}{ }^{1}$ criticizes Mr. Reade's conception of the physical state of the material below the crust : the wording of the passage quoted from Mr. Reade's book that this material is "solid by compression, but ready to flow one way or other, as the pressure may be reduced or increased," is certainly loose, but the context plainly shows Mr. Reade's conception of the material at about thirty miles depth to be that it is permanently plastic, and only kept from liquefaction by the pressure of a thirty mile crust above it. If the pressure were relieved, it would become liquid; if everywhere increased, it would become rigid; but if the plastic zone is deep, and a small area of the crust is weighted and depressed, the plastic material beneath may be displaced (without being made to flow as a liquid) and might have the effect of slightly bulging up the crust around the depressed area. This is Mr. Reade's view, but his use of the word flow suggests the idea of the liquidity which he did not mean to convey.

2. Mr. Fisher finds a second difficulty in the fact that the transference of heat from the plastic magma to the depressed crust would take place concurrently with the depression, "so that the swelling up (by expansion) would begin at once." Mr. Reade's own reply to this (Phil. Mag. 1891, p. 491) does not seem very happy: his own book (pp. 93 and 122) affords a better answer; for he says the first accession of heat would be employed in lateral expansion, and in folding and crushing the materials of the crust which underlay the newly-deposited sediments. He thinks the expansion of the lower layers of the weighted crust, being confined by the surrounding tracts and by the weight of the upper layers, would develope internal strains, and that much of the heat would be expended in doing work, i.e. in developing a force which would ultimately produce foliation by a process of forcible detrusion, crushing and repacking or reformation of constituents, when at length it became easier for the expansive force to lift the overlying mass of the crust rather than to exercise further lateral compression.

The above are Mr. Fisher's two principal objections to the theory of upheaval by cubical expansion, and he afterwards says, "If the two preliminary difficulties can be disposed of, the theory seems well suited to explain the formation of elevated plateaux. But for producing the intense corrugation, which characterizes most mountain ranges, the amount of horizontal expansion which it affords appears inadequate." In this remark I quite agree with him for reasons which will appear in the sequel.

3. Before, however, we can accept Mr. Reade's theory as a real cause of upheaval, we have to reckon with Mr. Davison, who has published what he regards as a fundamental objection to the theory. ${ }^{2}$ $\mathrm{He}$ writes, however, as if it was the accumulating sediment only that received an accession of heat, and as if the crust below did not partake in this accession. He says the heat which expands the
1 Dec. III. Vol. IV. p. 229, 1887.
1 Grol. Mag. May, 1891, p. 211. 
sediments must be withdrawn from the crust below, that this crust losing heat will contract, and that the expanding sediment will follow a retreating crust, so that no upheaval will take place at all, the total volume of crust and sediment remaining unaltered.

But these are not the conditions of Mr. Reade's theory. ${ }^{1}$ The crust is depressed by the weight of sediment, and it is the lower part of the original crust which is the first to expand by receiving heat from below. It is true that this only transfers the application of Mr. Davison's argument; the heat is conveyed from one layer to another, and if the crust is receiving heat from the plastic understratum, the latter will be cooled and lessened in volume unless its loss is made good. But what is to prevent the loss from being made good?

Mr. Fisher has a remark on this point which is quoted by Mr. Davison, though he avoids the consideration of it. $\mathrm{Mr}$. Fisher observes that "there can be no absolute increase in the amount of heat beneath the area in question except such as is supplied to it laterally." 2 This means that in his opinion some heat could be supplied laterally, and that heat lost by one part of the interior will be made good by the conduction of heat from the surrounding parts until the temperature of the whole is equalized; this may be a slow process, but it is surely a correct view, and one that Mr. Davison is bound to consider.

If the local loss of heat is thus distributed over the whole internal mass of the earth, there will be an absolute increase in the amount of heat below the sinking area, because the heat gained will be localized in the thickened crust. This thickened crust, composed partly of ancient crust material and partly of recent sediment, will expand; but how, in what manner, and to what extent, will it expand? These are the questions now before us.

Mr. Reade assumes that as soon as the depressed tract of crust begins to expand, the expansion will be localized and will form a ridge parallel to the longer diameter of the depressed area. $\mathrm{He}_{\mathrm{e}}$ rests this belief on the results of certain experiments and observations made on the expansion of metal plates which did so ridge up when heated. But the conditions of these experiments did not resemble those of a weighted crust free to bend downwards, and consequently they do not afford a sound basis for his relief.

The ridging up of the leaden floor of a pantry-sink exposed to alternate expansions and contractions by the contact of hot and cold water; or the heating of a sheet of lead which is screwed down to a block of wood, cannot afford any clue to the manner in which expansion would occur in a lenticular mass of material, heated from below, slowly sinking and able to expand in almost any direction, but especially in any upward direction. Without closely imitating

1 Mr. Davison informs me that his note had no special reference to Mr. Reade's book, but was simply a criticism on the "fundamental principle" of the expansion theory.

2 Physics of the Earth's Crust, second edition, p. 123, repeated from the first edition of 1881 . 
these conditions, it is impossible to say how such a mass would accommodate itself to the stresses set up by expansion, but it does not seem likely that a mass which is thickest in the centre would "buckle" or ridge itself up along a continuous diametric line; one would think that it was more likely to develope a set of concentric ridges near the edges, if any such ridges were produced at all.

It is quite possible that the crust below such a mass, being held circumferentially by the solid crust around it, would expand within its own area, and the internal compression resulting from this expansion might well produce some plication of the component rockbeds; the expansion would be greatest where the depression was greatest and the combined crust and sediment were thickest, but the plication would be greatest where the mass was thinnest and weakest, and there is no apparent reason why any part should throw itself into a great surface earth-wave; yet that is what Mr. Mellard Reade assumes it would do!

Again, if the expansion could be, or were likely to be, so localized as to cause a gigantic and continuons plication of the crust, the bending is not likely to be entirely upwards. Mr. Reade begins with assuming a plastic substratum; but when be comes to consider the expansion of the crust, he appears to assume a foundation which is rigid enough to support that crust without yielding to pressure. In all probability the compression which would cause an upward anticlinal swelling would force some other part of the bending crust still further downwards into the plastic substratum, and the most probable result would be a central anticline flanked by smaller synclinal plications. It is true that the total extent of the downward displacements would probably be less than that of the upward bulge, but any downward displacement will detract from the available upward expansion, and Mr. Reade requires all he can get for his mouvtain-building.

One of the most suggestive parts of Mr. Reade's book is his theory of plication by internal expansion (chapter xv.). He points out that if the corrugations of mountain chains have been formed by a compressive force acting from outside the orographic area, then the corrugated beds must originally have occupied a much wider space, the space in fact which they would now cover if pulled out straight. This is assumed by most geologists, and, taking it for granted, they have calculated that the breadth of country now occupied by the Alps has been shortened by 72 miles, and that occupied by the Appalachians has been shortened by 88 miles, that is to say, two spots, one on each side of the Appalachian Mountains, have been brought nearer to one another by 88 miles, and Mr. Reade asks whether geologists have fully realized what this means.

If, on the other hand, the plications are due or even largely due to the compression produced by the internal expansion of the mass, they result from actual lengthening of the strata throughout the whole breadth of the orographic area, and consequently they do not involve any lateral movement in space. This seems to me a point that is well worth consideration. 
It is a question, however, whether the plications are wholly formed by expansive compression; if they are, then they become a measure of the expansion. Now in the case of the Alps the calculated shortening is nearly as great as the actual width of the range; in other words, the expansion must have loubled the length of the beds laterally; to do this it must have doubled the volume of the solid mass out of which the range was formed. Let us apply this result to an area of the size used by Mr. Reade for illustrative calculation, viz. one measuring $500 \times 500 \times 20$ miles, which is equal to 500,000 cubic miles. Now if this is doubled by expansion, 500,000 cubic miles has been added to the mass, but the calculated expansion of such a block raised by $1000^{\circ} \mathrm{F}$. is only 78,400 cubic miles, and is therefore very far short of the required amount. The conolusion I would draw from this little calculation is that the plications are not wholly due to expansion.

Finally, it seems desirable to point out to Mr. Reade that the assumption of a plastic substratum will not satisfy Sir W. Thomson's demands for the rigidity of the Earth as a whole. Mr. Reade cannot have a substratum that is plastic enough to yield to such a small terrestrial influence as the local accumulation of sediment, while it is rigid enough to resist the deforming tidal influences of the sun and moon. The only way out of this difficulty is the assumption of a liquid substratum saturated with dissolved gas: this is Mr. Fisher's view, and it affords a much more satisfactory basis for the explanation of terrestrial movements.

Postscript.-Correspondence with Mr. Davison leads me to see that although the temperature of the mass below the depressed area will be raised by conduction of heat from the surrounding parts, yet that these surrounding parts will contract in parting with heat; consequently if this conduction is fairly rapid and the further equalization of temperature is a slow process, the mass which is receiving heat may expand laterally into the spaces formed by the contraction of the parts immediately outside it, instead of expanding upwarls and raising the depressed crust. Mr. Davison therefore still maintains that no upheaval wonld result from the expansion of a depressed portion of the crust, and until his argument can be answered it certainly cuts at the root of the expansion theory of surface upheavals.

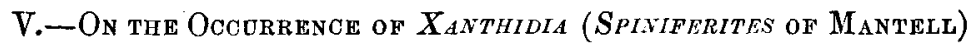
in the London Clay of the Isle of Sheppey.

By E. W. WeTHERELL, F.G.S.

THE vexed question of the affinities of the fossil organisms known as Xanthidia-a question which only experienced zoologists and botanists can hope to solve-will not be discussed in this short paper, my intention being merely to show that these interesting organisms are not confined (in England) to the Chalk flints and Grey Chalk, but exist in the London Clay, and to give a short account 